\title{
Development and Characterization of Horse Bone-derived Natural Calcium Phosphate Powders
}

\author{
Kyoung-Je Jang ${ }^{1 \dagger}$, Woo Jae Cho ${ }^{1 \dagger}$, Hoon Seonwoo ${ }^{1}$, Jangho Kim ${ }^{1}$, Ki Taek Lim$^{1}$, \\ Pill-Hoon Chung ${ }^{3,4}$, Jong Hoon Chung ${ }^{1,2 *}$ \\ ${ }^{1}$ Department of Biosystems \& Biomaterials Science and Engineering, Seoul National University, \\ Seoul, 151-742, Republic of Korea. \\ ${ }^{2}$ Research Institute of Agriculture and Life Sciences, Seoul National University, Seoul, Korea \\ ${ }^{3}$ Department of Oral and Maxillofacial Surgery and Dental Research Institute, School of Dentistry, \\ Seoul National University, Seoul, Korea \\ ${ }^{4}$ Tooth Bioengineering National Research Laboratory of Post BK21, School of Dentistry, \\ Seoul National University, Seoul, Korea
}

Received: May $16^{\text {th }}$ 2014; Revised: May $27^{\text {th }} 2014$; Accepted: May $27^{\text {th }} 2014$

\section{Abstract}

Purpose: This study was to develop an effective process for fabricating biocompatible calcium phosphate powders (CPPs) using horse bones, and to investigate the characteristics of them. Methods: The characteristics of horse bone powders (HBPs) were investigated according to the different osseous tissue types (compact bone and cancellous bone), bone types (spine and tibia), pretreatment methods (cold water, $\mathrm{H}_{2} \mathrm{O}_{2}$, and hot water), sintering time $(4,8$ and $12 \mathrm{~h}$ ), and sintering temperature $\left(600,900,1100\right.$ and $\left.1300^{\circ} \mathrm{C}\right)$. In addition, the grinding methods were compared based on the wet grinding (ball mill) and dry grinding (blade grinder) method to make it as powders. Finally, their cytotoxicity and cell viability were checked. Results: Regardless of the types of osseous tissues and bones, HBPs were well fabricated as biocompatible CPPs. It was also found that the pretreatment methods did not influence on the resultants, showing well-fabricated HBPs. Considering the processing time, the hot water method was the most suitable compared to other pretreatment methods. Further, $12 \mathrm{~h}$-sintering time was sufficient to remove residual organic compounds. The sintering temperatures greatly affected the properties of bone powders fabricated. The x-ray diffraction (XRD) peak of horse bone sintered at $600^{\circ} \mathrm{C}$ was most closed to that of hydroxyapatite (HA). Our bioactivity study demonstrated that the HBPs fabricated by sintering horse bones at $1300^{\circ} \mathrm{C}$ showed the best performance in terms of cell viability whereas the HBPs $1100^{\circ} \mathrm{C}$ showed the cytotoxicity. Conclusions: Using various types of horse bone tissues, biocompatible CPPs were successfully developed. We conclude that the HBPs may have a great potential as biomaterials for various biological applications including bone tissue engineering.

Keywords: Grinding process, Horse bone powder, Sintered horse bone, Sintering temperature

\section{Introduction}

Tissue engineering is defined as an interdisciplinary field that applies the principles of engineering and the life sciences toward the development of biological substitutes

\footnotetext{
${ }^{\dagger}$ These authors contributed equally to this work.

*Comesponding author: Jong Hoon Chung

Tel: +82-2-880-4601; Fax: +82-2-880-4601

E-mail: jchung@snu.ac.kr
}

that restore, maintain, or improve tissue function (Langer \& Vacanti, 1993; Skalak \& Fox, 1988). In recent years, the importance of bone tissue engineering has grown as the number of bone defects and bone fracture has increased due to the aging society. For instance, Johnell and Kanis reported that there were 9.0 million patients worldwide in the osteoporotic fractures only in 2000 (Johnell \& Kanis, 2006). Accordingly, in bone tissue engineering, bone replacement grafts have emerged for bone reconstruction 
and bone healing. The bone replacement grafts are classified by four groups: autograft, allograft, xenograft, and alloplast. Autograft is the bone graft using the autogenous bone. Allograft uses the bones from the same species. Since there is least immune response, the two surgical methods are usually preferred. However, they still have some limitations such as difficulty in obtaining, high cost, complex surgical procedure, and the risk of infection (Betz, 2002; Moore, Graves, \& Bain, 2001).

Xenograft obtains the grafting materials from other species like bovine or porcine. The merits of the method, in comparison to autograft and allograft, are relative ease to obtain raw materials (e.g., cow and pig) with low cost. However, xenograft has obvious disadvantages; for example, the immune reaction and the risk of infection were always exposed to the patients. To overcome this limitation, Taniguchi et al. conducted the surgical implantation using sintered bovine bone. In that study, they reported that the sintered bovine bones did not cause the infection or fracture, suggesting that the sintered animal bones have great potentials as a suitable engraftment material for bone repair and bone regeneration (Taniguchi, Tamaki, Oura, Hashizume, \& Minamide, 1999). Distinctively, the sintered animal bones were mainly composed of hydroxyapatite (HA), which predominantly consists of human bone (Moore et al., 2001; Sobczak, Kowalski, \& Wzorek, 2009). As a consequence, it has widely been suggested that the bone substitutes can be obtained by animal bones or teeth. That is, naturally derived calcium phosphate-based biomaterials (CPBs) can be easily fabricated with advantages, such as cheap raw materials, low production cost, and better biological properties compared to the synthetic HA, for bone repair or regeneration in both humans and animals (Guizzardi et al., 2000; Mezahi et al., 2009).

Based on these advantages, tremendous CPBs have been developed from various types of species, e.g. porcine bone (Im, Chung, Lim, Choung, \& Hong, 2007; Janus, Faryna, Haberko, Rakowska, \& Panz, 2008; Sobczak et al., 2009), bovine bone (Barakat et al., 2008; Mezahi et al., 2009; Sobczak et al., 2009; Taniguchi et al., 1999; Tsai et al., 2010; Ueno et al., 1983), chicken bone (Kim, Rey, \& Glimcher, 1996), and fish bone and scales (Mondal, Mondal, Dey, \& Mukhopadhyay, 2012; Ozawa \& Suzuki, 2002). In addition, it was reported that the characteristics of HA derived from biowastes could be altered by various conditions, such as the types of osseous tissue (i.e. compact bone and cancellous bone) (X.-Y. Wang, Zuo, Huang, Hou, \& Li,
2010) and bone (tibia and spine) (Laird, 2010; Sobczak et al., 2009), pretreatment methods (Barakat et al., 2008; Sobczak et al., 2009), and sintering conditions (Danilchenko, Koropov, Protsenko, Sulkio-Cleff, \& Sukhodub, 2006; Ooi, Hamdi, \& Ramesh, 2007). However, horse bones still have been overlooked despite its potential as a bioresource for manufacturing the natural CPBs.

Based by these considerations, in this study, natural CPBs derived from horse bones were developed and evaluated to verify the potential as a new bioresource for CPBs using physiochemical characterizations (Barakat et al., 2008; Fernandez-Moran \& Engstrom, 1957; Janus et al., 2008; Kim et al., 1996; Panda, Pramanik, \& Sukla, 2013) and biological studies (Guizzardi et al., 2000; Im et al., 2007; Tsai et al., 2010). To this end, we first developed an optimum processing condition for fabricating horse bone-derived CPBs (hCPBs). Various factors (the types of osseous tissue and bone, pretreatment methods, sintering time, and sintering temperature) were examined. The grinding conditions (i.e., two types of grinding, a ball mill (wet) and a blade grinder (dry)) were also investigated for fabrication of high-quality of horse bone powders (HBPs) Finally, biological activity studies in terms of cell cytotoxicity and proliferation test were investigated to reveal their potentials as a bone engraftment material using MC3T3-E1 cell line, which is well known as an in vitro model for osteoblast development (Quarles, Yohay, Lever, Caton, \& Wenstrup, 1992; J. Wang, de Boer, \& de Groot, 2008).

\section{Materials and Methods}

\section{General preparation process}

Horse bone was originated from the slaughterhouse (Jeju, Republic of Korea). It is initially cut into pieces with approximately $2 \sim 3 \mathrm{~cm}$ to put the pieces into the crucible. Next, the bone pieces were soaked in distilled water for 48 hour to drain blood and surface flesh was cut out. This process was adapted commonly in all preparing process.

\section{Characteristics according to the pretreatment methods}

After general preparation process, three different pretreatment methods were adapted: immersion in (1) cold water, (2) $\mathrm{H}_{2} \mathrm{O}_{2}$, and (3) hot water. Each condition was described as follows. 
1) Cold water method (CW): The horse bone pieces underwent the general preparation process was immersed in water at the room temperature for 48 hour.

2) $\mathrm{H}_{2} \mathrm{O}_{2}$ method: It was the same method in previous study reported by Im et al. (Im et al., 2007). Briefly, the horse bone pieces underwent the general preparation process were immersed in $\mathrm{H}_{2} \mathrm{O}_{2}$ (\#7722-84-81, Duksan chemicals co., Korea) for 48 hour.

3) Hot water method (HW): The horse bone pieces underwent the general preparation were immersed in boiling water at $1 \mathrm{~atm}$ for 2 hours.

Fourier transform infrared spectroscopy (FT-IR) and X-ray diffraction (XRD) analysis

FT-IR was measured to confirm the presence of anions partially substituting $\mathrm{PO}_{4}{ }^{3-}$ and $\mathrm{OH}^{-}$groups and the elimination of organic compounds. Transmission IR spectra were recorded from $4000-650 \mathrm{~cm}^{-1}$ with a resolution of $8 \mathrm{~cm}^{-1}$ using a FT-IR spectrometer (Nicolet 6700 , Thermo Scientific, USA). XRD was used to examine the crystal structure of the sintered HBPs. The XRD patterns were recorded with a powder X-ray diffractometer (D8 ADVANCE with DAVINCI, Bruker, Germany) with $\mathrm{Cu}-\mathrm{K} \alpha$ radiation ( $\lambda$ $=0.154 \mathrm{~nm}$ ) at $40 \mathrm{kV}$ and $40 \mathrm{~mA}$. Scans were obtained from 20 to $60^{\circ} 2 \theta$ in $1^{\circ} / \mathrm{min}$. The crystalline phase compositions were identified with reference to standard joint committee on powder diffraction standards (JCPDS) cards available in the system software.

\section{$X$-ray fluorescence spectrometry (XRF)}

XRF (S4 PIONEER, Bruker AXS, Germany) was used to obtain the elemental chemical composition of HBPs.

\section{Morphological observation}

The surface morphologies of the resultants were observed using a field-emission scanning electron microscope (FE-SEM) (SUPRA 55VP, Carl Zeiss, Germany).

\section{Characteristics according to osseous tissue type and bone type}

\section{Sample preparation}

After general preparation process, the traditional preparation process used for porcine bones in our previous study (Baik, 2011; Im et al., 2007) was carried out to horse bone pieces. Briefly, the horse bone samples were initially prepared according to the bone types (i.e., spine and tibia) and osseous tissue types (i.e., compact bone and cancellous bone). After initial preparation, the horse bone samples were immersed in $\mathrm{H}_{2} \mathrm{O}_{2}$ (\#7722-84-81, Duksan chemicals co., Korea) for $48 \mathrm{~h}$ and dried. After drying, the horse bone was sintered in the electric furnace (UP350E, Yokogawa Co, Japan) at $1200^{\circ} \mathrm{C}$ for $2 \mathrm{~h}$. Then, the sintered bone was ground into powder with using a miller (A10, IKA, Germany), and the fabricated HBPs were sintered by two times more as described before. The animal bone powder was classified by particle size using $100 \mu \mathrm{m}$-sieves (Daihan Scientific, Korea). For the comparative study, the outputs according to pretreatment methods were compared by FT-IR, XRD, XRF, and FE-SEM. Synthetic HA (289396, Sigma-aldrich, USA) was used as control.

\section{Fine powder production}

For the fine powder production, the two types of grinding (ball mill and blade grinding) were compared. As a ball mill, Planetary Mono Mill PULVERISETTE 6 classic line (Fritsch, Germany) was used. As a blade

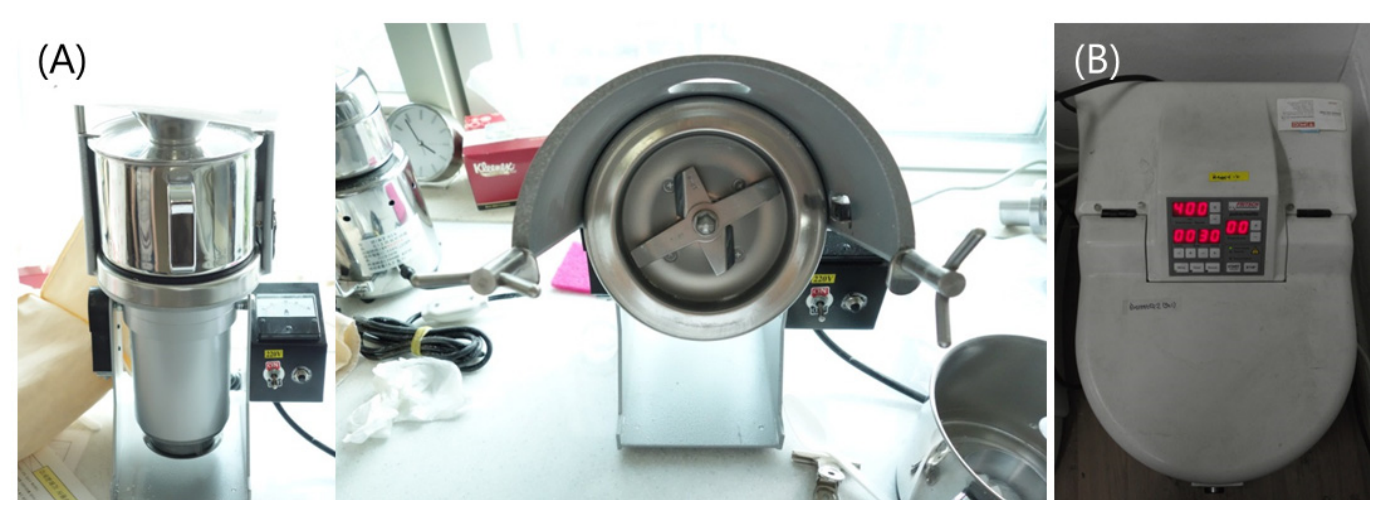

Figure 1. Two types of grinding machines. (A) Blade grinder (dry grinding, ALG-2) and (B) Ball mill (wet grinding, Planetary Mono Mill PULVERISETTE 6 classic line). 
grinder, air leading grinding machine (ALG-2, Mill Powder Tech, Taiwan) was used. The particle sizes of the animal bone powders were checked using a particle size analyzer (Mastersizer S, Malvern Instruments Ltd, UK) and FE-SEM.

\section{Characteristics according to the sintering conditions}

Thermal gravimetric analysis (TGA) of HBPs

The thermal gravimetric analysis of the horse bone was carried out to observe the thermal changes of HBPs according to the temperature using a thermal gravimetric analyzer (SDT Q600, TA Instruments, USA) over a temperature range of $25-1,300^{\circ} \mathrm{C}$ with a heating rate of $10^{\circ} \mathrm{C} / \mathrm{min}$.

\section{Sample preparation}

Besides the bone types and pretreatment methods, the sintering temperature and time were verified to optimize the production process of natural CPBs derived from horse bone. Based on the TGA results, the sintering temperature was selected: $600^{\circ} \mathrm{C}, 900^{\circ} \mathrm{C}, 1100^{\circ} \mathrm{C}$, and $1300^{\circ} \mathrm{C}$. All of the sintering process were carried out using the alumina crucible with $10 \mathrm{~cm} \times 10 \mathrm{~cm} \times 5 \mathrm{~cm}$ (width $\times$ depth $\times$ height). The weight of samples was about $85 \mathrm{~g}$ typically. For the selection of the sintering time that enable to remove the organic compounds enough, the sintering process was carried out at the minimal temperature $\left(600^{\circ} \mathrm{C}\right)$ with 3 steps and 4 hours for each step. For the comparative study, the outputs according to sintering conditions were compared by FT-IR, XRD, XRF, and FE-SEM.

\section{In vitro test}

\section{Cell culture}

A mouse calvaria-derived osteoblast cell line, MC3T3-E1 (CRL-2593, ATCC, USA) was cultured in proliferation media. The proliferation media was $\alpha$-MEM (\#LM 008-02, WELGENE Inc., Korea) supplemented with $10 \%$ fetal bovine serum (FBS, \#SH30919.03, Hyclone, USA), 1\% antibiotics (\#LS 203-01, WELGENE Inc., Korea) at $37^{\circ} \mathrm{C}$ in $5 \% \mathrm{CO}_{2}$ conditions. The media was changed every other two day.

\section{Cytotoxicity test}

Cell cytotoxicity was assessed to verify the effect of HBPs on cell cytotoxicity according to sintering temperature. The study was carried out with an EZ-Cytox cell viability assay kit (\#EZ3000, Daeillab Service Co., Korea) according to manufacturer's instructions. For the cell cytotoxicity test, the extraction media were prepared by immersion of the samples in the proliferation media for 24 hours. $1 \times$ $10^{4}$ cells in $100 \mu \mathrm{L}$ of culture media were seeded in a 96 well plate with the extraction media in triplicate and incubated at $37^{\circ} \mathrm{C}$ in $5 \% \mathrm{CO}_{2}$ conditions. After 24 hours of cell seeding, media were changed by fresh media and 10 $\mu \mathrm{L}$ of the EZ-Cytox reagent was added. After 2 hourincubation at $37^{\circ} \mathrm{C}$ in $5 \% \mathrm{CO}_{2}$ conditions, the optical densities of the plates were analyzed by a microplate absorbance reader (Sunrise, Tecan, Australia) at 450nm.

\section{Cell viability test}

Cell viability was assessed to verify the effect of HBPs on cell viability according to sintering temperature. The study was carried out with an EZ-Cytox cell viability assay kit according to the protocol given in the instructions. Animal bone powders and the control groups were coated on the surface of a 24 well plate with the polydimethylsiloxane (PDMS, SYLGARD 184 SILICONE ELASTOMER KIT, Dow Corning, USA) in triplicate. After the coating, $3 \times 10^{4}$ cells were seeded on each well and incubated for 1, 4, and 7 days, and the media was changed every other two day. For cell viability test, an EZ-Cytox cell viability assay kit (\#EZ3000, Daeillab Service Co., Korea) was used. After the incubation of 1, 4, and 7 days, media were changed by fresh media and $500 \mu \mathrm{L}$ of the EZ-Cytox reagent was added. After $2 \mathrm{~h}$ incubation at $37^{\circ} \mathrm{C}$ in $5 \% \mathrm{CO}_{2}$ conditions, the optical densities of the plates were analyzed by a microplate absorbance reader (Sunrise, Tecan, Australia) at $450 \mathrm{~nm}$.

For morphological observation of the cells on the coating, $6 \times 10^{4}$ cells were seeded on the coated 24 well plate and incubated for 1 day at $37^{\circ} \mathrm{C}$ in $5 \% \mathrm{CO}_{2}$ conditions. Then, $2 \mathrm{~mL}$ of modified karnovsky's fixative solution was filled in the 24 well plate and stored for 2 hours at $4^{\circ} \mathrm{C}$ for primary fixation. The primary fixing solution was then removed, and the cultured bone cement specimens were washed with $0.05 \mathrm{M}$ sodium cacodylate buffer three times at $4^{\circ} \mathrm{C}$ for $10 \mathrm{~min}$. The specimens were soaked in $2 \mathrm{~mL}$ of $1 \%$ osmium tetroxide solution for 2 hours for post fixation. After the solution was removed, the plate was washed two times briefly with distilled water at a room temperature. The specimens were dehydrated in 30,50 , $70,80,90$, and $100 \%$ ethanol at room temperature for 10 min., respectively. After soaking in hexamethyldisilazane (HMDS) for 15min two times for drying, FE-SEM analysis 
was carried out with a Zeiss Supra 55VP field-emission scanning electron microscope.

\section{Statistical data analysis}

Statistical analysis was carried out using the statistical analysis system (SAS) for Windows v9.3 (SAS Institute, Inc., USA). Statistical significance between control and treatment groups was compared with two-way ANOVA at ${ }^{*} \mathrm{p}<0.05$. The data were reported as the mean \pm standard deviation, $\mathrm{n}=3$.

\section{Results and Discussion}

\section{Characteristics according to the pretreatment methods}

\section{FT-IR and XRD results}

Figure 2(a) showed the bands at $3640-3560 \mathrm{~cm}^{-1}$, and 1088-962 $\mathrm{cm}^{-1}$, indicating $\mathrm{OH}$ and $\mathrm{PO}_{4}{ }^{3-}$ group, respectively.
No different bands were displayed according to the pretreatment methods. Figure 2(b) showed XRD patterns according to the pretreatment methods. In the XRD patterns, the peaks were observed in same $2 \theta$. The presence of $\mathrm{CaO}$ was also observed in all of the pretreatment methods.

\section{XRF results}

The chemical compositions according to pretreatment methods were presented in Table 1. Calcium, oxygen, and phosphate are the main components and there were some other minor components. The calcium was significantly low, while phosphate was significantly high in the hot water method. It was widely known that the ionic components of hydroxyapatite such as $\mathrm{Ca}^{2+}$ can readily be exchanged by other ions (Bahrololoom, Javidi, Javadpour, \& Ma, 2009). Considering the significantly high contents of $\mathrm{Na}$ and $\mathrm{K}$, it would be assumed that the $\mathrm{Ca}^{2+}$ components of hydroxyapatite were substituted by $\mathrm{Na}$ and $\mathrm{K}$ due to the

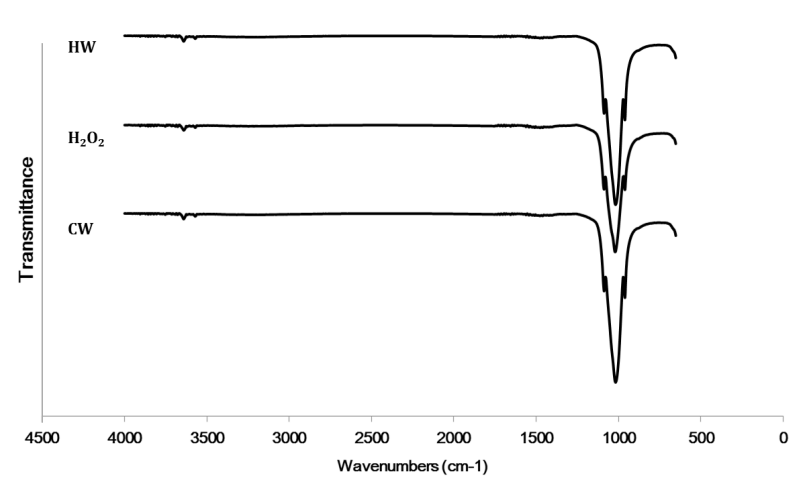

(a)

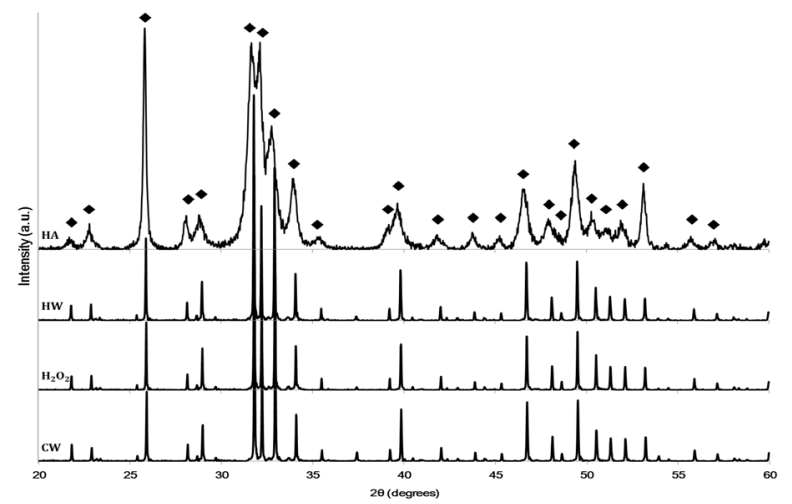

(b)

Figure 2. (a) FTIR spectra according to the pretreatment methods. (HW: hot water, CW: cold water) (b) XRD patterns according to the pretreatment methods. (HW: hot water, CW: cold water, $\diamond$ : Characteristic peaks of hydroxyapatite).

\section{Table 1. Elemental composition according to the pretreatment methods (HW: hot water, CW: cold water)}

\begin{tabular}{|c|c|c|c|c|c|c|}
\hline \multirow{3}{*}{$\begin{array}{c}\text { Formula } \\
\qquad \mathrm{Ca}\end{array}$} & \multicolumn{6}{|c|}{ Concentration (wt.\%) } \\
\hline & \multicolumn{2}{|c|}{$\mathrm{CW}$} & \multicolumn{2}{|c|}{$\mathrm{H}_{2} \mathrm{O}_{2}$} & \multicolumn{2}{|c|}{$\mathrm{HW}$} \\
\hline & 44.023 & \pm 0.107 & 44.047 & \pm 0.085 & *43.587 & \pm 0.051 \\
\hline $\mathrm{O}$ & 38.700 & \pm 0.000 & 38.667 & \pm 0.058 & 38.767 & \pm 0.058 \\
\hline $\mathrm{P}$ & 15.827 & \pm 0.055 & 15.760 & \pm 0.046 & *15.967 & \pm 0.035 \\
\hline $\mathrm{Na}$ & 0.818 & \pm 0.003 & 0.856 & \pm 0.011 & *0.978 & \pm 0.018 \\
\hline $\mathrm{Mg}$ & ${ }^{*} 0.410$ & \pm 0.006 & 0.474 & \pm 0.005 & 0.454 & \pm 0.003 \\
\hline $\mathrm{Al}$ & 0.020 & \pm 0.006 & 0.009 & \pm 0.016 & 0.018 & \pm 0.016 \\
\hline Others & 0.228 & \pm 0.017 & 0.209 & \pm 0.022 & 0.230 & \pm 0.001 \\
\hline $\mathrm{Ca} / \mathrm{P}$ molar ratio & \multicolumn{2}{|c|}{2.150} & \multicolumn{2}{|c|}{2.160} & \multicolumn{2}{|c|}{2.110} \\
\hline
\end{tabular}

${ }^{*}, \mathrm{p}<0.05$ 
high temperature of hot water method.

Our results indicated that there were no significant differences in FT-IR and XRD results according to the pretreatment methods, suggesting that the pretreatment methods did not strongly influence the chemical components of bone powders fabricated. Based on these results, we suggest that the hot water method is recommended as a suitable pretreatment method for fabrication of horse bone powders.

\section{Characteristics according to osseous tissue type and bone type}

\section{FT-IR}

The FT-IR band results indicated that compact and cancellous bones are very similar (data not shown). There were weak bands around at $3567 \mathrm{~cm}^{-1}$ and $1540 \mathrm{~cm}^{-1}$, and strong bands around at $1089 \mathrm{~cm}^{-1}, 1014 \mathrm{~cm}^{-1}$, and $960 \mathrm{~cm}^{-1}$. The band around at $3567 \mathrm{~cm}^{-1}$ was due to the $\mathrm{O}-\mathrm{H}$ stretch of the $\mathrm{OH}$ group in the hydroxyapatite. The bands around at $1540 \mathrm{~cm}^{-1}$ indicated $\mathrm{CO}_{3}{ }^{2-}$ originated from the mineral constituent present in the sample. The bands around at $1089 \mathrm{~cm}^{-1}, 1014 \mathrm{~cm}^{-1}$, and $960 \mathrm{~cm}^{-1}$ indicated the $\mathrm{PO}_{4}{ }^{3-}$ (Laird, 2010). The FT-IR results showed that they have similar band trends in compact bone and cancellous bone.

The FT-IR bands of the samples from spine and tibia are very similar to Figure 2(a) (data not shown). Almost same bands with the compact bone and cancellous bones were shown, but the FT-IR spectra from the spine sample showed the absence of the bands around at $3567 \mathrm{~cm}^{-1}$ and $1540 \mathrm{~cm}^{-1}$. However, the bands around at $3567 \mathrm{~cm}^{-1}$ and
$1540 \mathrm{~cm}^{-1}$ showed weak intensities, attributed to the small amounts of the band groups.

\section{$X R D$ results}

XRD analysis of the samples was displayed with that of the synthetic hydroxyapatite as a control. Figure 3(a) showed the XRD patterns of the osseous tissue types. The patterns of the compact and cancellous bones showed the presence of peaks in same $2 \theta$. Also, most of their patterns corresponded to the patterns of the synthetic HA. Interestingly, small peaks at $37^{\circ}$, indicating the presence of $\mathrm{CaO}$ clearly showed typical characteristics of sintered bone (Rodrigues et al., 2003). Figure 3(b) showed the XRD patterns of the bone types showing almost same results with those of the osseous tissue types. Almost same results with synthetic $\mathrm{HA}$ were appeared and there were the peaks of $\mathrm{CaO}$, too.

\section{XRF results}

$\mathrm{XRF}$ analysis was carried out to figure out the chemical compositions. The chemical compositions of compact bone and cancellous bone were presented in Table 2. As seen, calcium, oxygen and phosphatewere the main components. Some minor components such as sodium or magnesium were also present. There were significant differences in $\mathrm{Mg}$, $\mathrm{Al}$, and $\mathrm{K}$ while other components showed no significance.

The chemical compositions of spine and tibia were presented in Table 2. They also showed $\mathrm{Ca}, \mathrm{O}$, and $\mathrm{P}$ as major components and others as minor components showing no significant differences between spine and tibia.

Based on these results, we have learned that the effects of the type of osseous tissues and bones may not be a

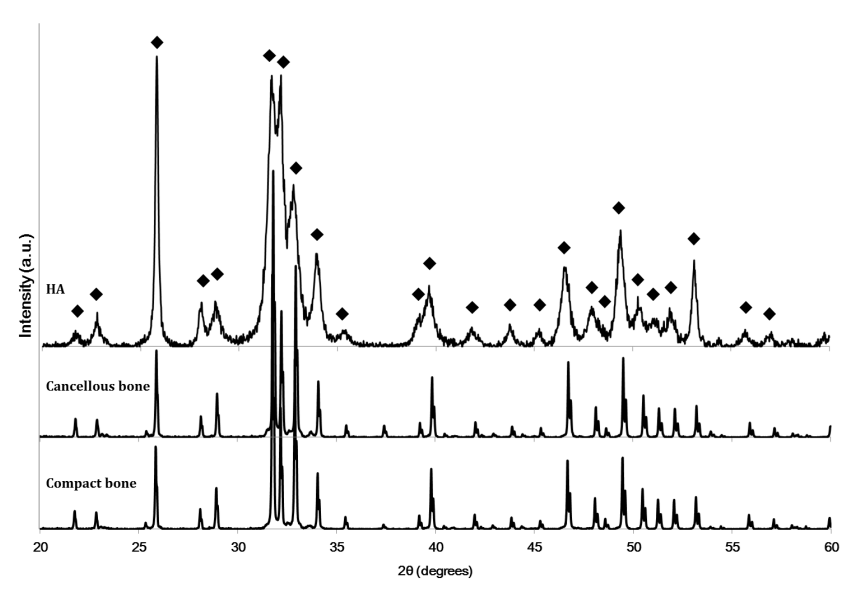

(a)

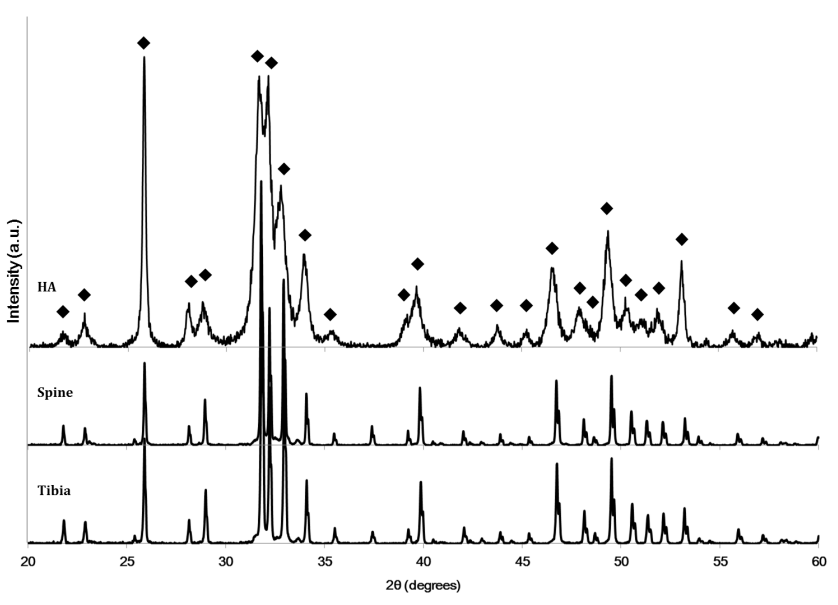

(b)

Figure 3. (a) XRD patterns according to the osseous tissue types and synthetic HA. (b) XRD patterns according to the bone types and synthetic HA. ( $\diamond$ : Characteristic peaks of hydroxyapatite). 
Table 2. Elemental composition according to the osseous tissue types and bone types

\begin{tabular}{|c|c|c|c|c|c|c|c|c|}
\hline \multirow{3}{*}{ Formula } & \multicolumn{8}{|c|}{ Concentration (wt.\%) } \\
\hline & \multicolumn{2}{|c|}{ Compact bone } & \multicolumn{2}{|c|}{ Cancellous bone } & \multicolumn{2}{|c|}{ Spine } & \multicolumn{2}{|c|}{ Tibia } \\
\hline & & \pm S.D. & & \pm S.D. & & $\pm S . D$ & & $\pm S . D$ \\
\hline $\mathrm{Ca}$ & 41.433 & 0.188 & 42.747 & 1.107 & 43.833 & 2.826 & 42.070 & 0.503 \\
\hline $\mathrm{O}$ & 39.400 & 0.173 & 39.267 & 0.289 & 38.867 & 0.896 & 39.433 & 0.153 \\
\hline$P$ & 16.717 & 0.351 & 16.650 & 0.485 & 15.650 & 0.779 & 16.897 & 0.169 \\
\hline $\mathrm{Na}$ & 1.096 & 0.164 & 0.491 & 0.387 & 0.335 & 0.163 & 0.571 & 0.082 \\
\hline $\mathrm{Mg}$ & 0.567 & 0.019 & $0.521^{*}$ & 0.016 & 0.460 & 0.060 & 0.528 & 0.033 \\
\hline $\mathrm{Al}$ & 0.297 & 0.072 & $0.000^{*}$ & 0.000 & 0.158 & 0.273 & 0.076 & 0.132 \\
\hline Others & 0.503 & 0.173 & 0.326 & 0.102 & 0.699 & 0.842 & 0.404 & 0.153 \\
\hline $\mathrm{Ca} / \mathrm{P}$ molar ratio & \multicolumn{2}{|c|}{1.916} & \multicolumn{2}{|c|}{1.984} & \multicolumn{2}{|c|}{2.165} & \multicolumn{2}{|c|}{1.924} \\
\hline
\end{tabular}

*, $p<0.05$

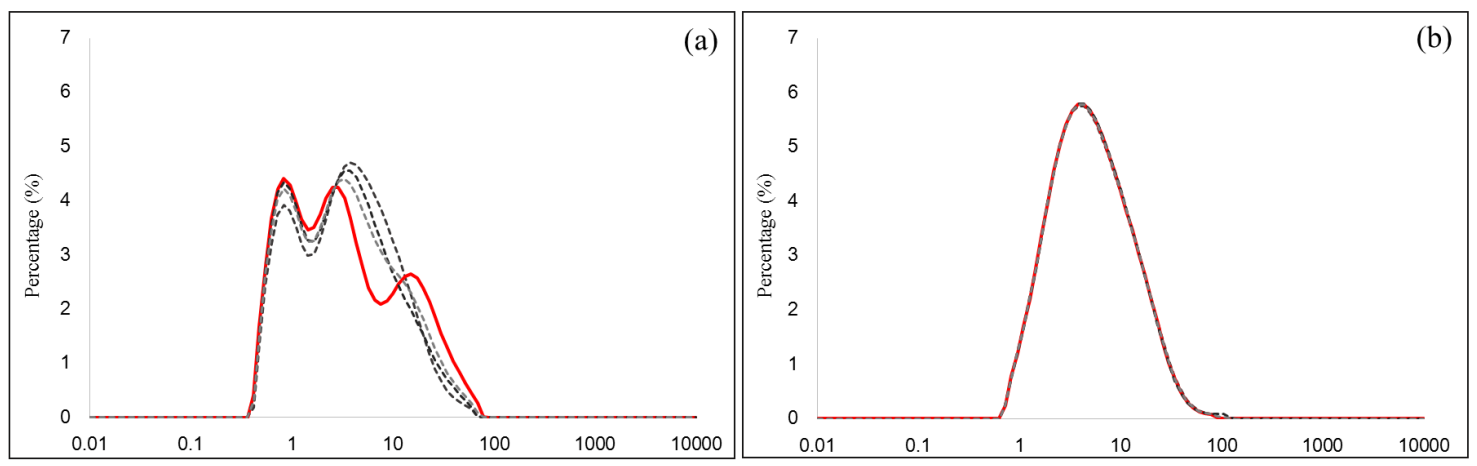

Figure 4. The particle distribution of (a) ball mill (wet grinding) and (b) blade grinder (dry grinding).
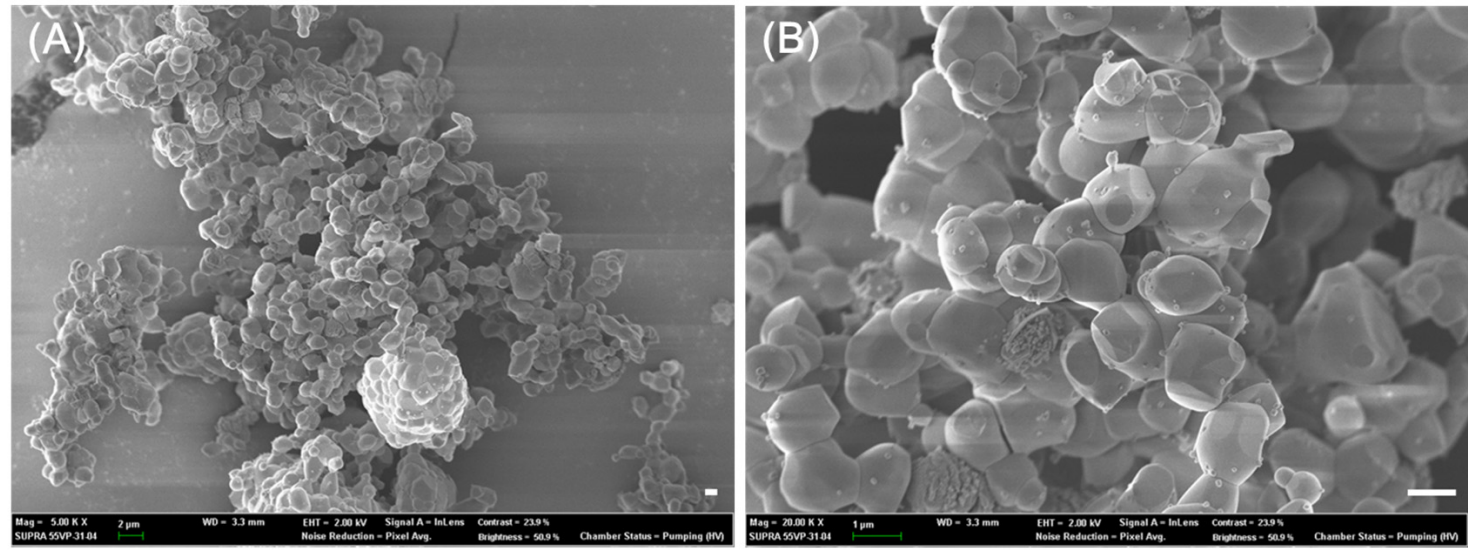

Figure 5. SEM images of the powders from blade grinder method with (A) x5000 magnification and (B) x20000 magnification.

critical factor for the fabrication of HBPs. Namely, both osseous tissues and bones can be used as appropriate sources to fabricate HBPs.

\section{Grinding methods}

A grinding process to obtain optimal method was investigated to prepare regular size-HBPs. To this end, two types of grinder, ball mill and blade grinder were used. Once HBPs were ground, their particle size and distribution were analyzed by the Malvern Mastersizer S. As shown in Figure 4, average particle sizes ground by ball mill method and blade grinder method were $2.888 \mu \mathrm{m}$ and $4.527 \mu \mathrm{m}$, respectively, showing that particles made by blade grinder were moderately larger than that of ball 
mill. By the way, the particle distributions by blade grinder were closer to the normal distribution than that of ball mill. When the powders from the blade grinder method was watched by FE-SEM images, it is shown that nanoscale-HBPs were aggregated each other, resulting in $\sim 5 \mu \mathrm{m}$ particle (Figure 5).

Considering those results, the blade grinding method seems more advantageous than ball mill method. (1) Although average particle size of grinder method is larger than that of ball mill method, it makes HBPs more regularly. (2) It can produce nanoscale-HBPs, either. It was reported that the nano-sized hydroxyapatite showed better cell proliferation and inhibition of cell apoptosis (Cai et al., 2007; Shi, Huang, Cai, Tang, \& Yang, 2009). Although aggregation of nanoscale-HBPs remained to be overcome, it is anticipated that they would be helpful to bone regeneration. (3) Above all, the work efficiency blade grinder method ( $2 \mathrm{~kg} /$ hour) was around 2 order of magnitude higher than that of ball mill method (50g/hour). Consequently, we can conclude that the blade grinder method would be better than the ball mill method.

\section{Sintering conditions}

\section{Selection of sintering time and sintering temperature}

As implantable biomaterials, HBPs should be sintered enough to eliminate residual organic compounds for evading immune response. Hence we assessed minimal sintering time that can thoroughly remove all organic compounds. Sintering times were chosen for 3 steps: 4,8 , and 12 hours. Each of the residual organic compounds was analyzed by FT-IR and the results were shown in Figure 6(a). The broad band at $3448 \mathrm{~cm}^{-1}$ was shown in the spectrum of step 1 (4 hour-sintering), which was assigned to the $\mathrm{O}-\mathrm{H}$ stretch of water. The bands at 2205 $\mathrm{cm}^{-1}$ and $2106 \mathrm{~cm}^{-1}$ were assigned to the carbonyl stretch associated with the presence of aliphatic fatty acid. The broad and high bands at $1545 \mathrm{~cm}^{-1}$ and $1465 \mathrm{~cm}^{-1}$ were assigned to residual organic material although there would be a contribution from $\mathrm{CO}_{3}{ }^{2-}$. The bands under the $700 \mathrm{~cm}^{-1}$ were assigned to the $\mathrm{CH}$ groups in organic compounds (Laird, 2010). In the spectrum of step 2 (8 hour-sintering), there was no band related to the fatty acid and water, but weak bands at around $700 \mathrm{~cm}^{-1}$ due to the residual organic material were observed. In the spectrum of step 3 (12 hour-sintering), all of the bands related to the organic compounds were discarded. Consequently, sintering time should exceed at least 12 hours to remove residual organic compounds thoroughly.

Sintering temperature is also investigated. First, the sintering temperature was selected based on the TGA curve (Figure 6(b)). In the TGA results, the derivative weight had a relationship with thermal changes. The weight changes at $111.62^{\circ} \mathrm{C}$ is related to the water evaporation (A), and the weight changes at $351.11^{\circ} \mathrm{C}$ is related to the thermal reaction of organic compounds (B). Its derivative weight change is almost 0 around $600^{\circ} \mathrm{C}$. From the results, sintering at $600^{\circ} \mathrm{C}$ seemed to be enough to eliminate the organic compounds (C). At $868.19^{\circ} \mathrm{C}$, there was a weight change that would assigned to the chemical decomposition (D). And there was additional chemical decomposition at $1132.36^{\circ} \mathrm{C}$ (E). Therefore,

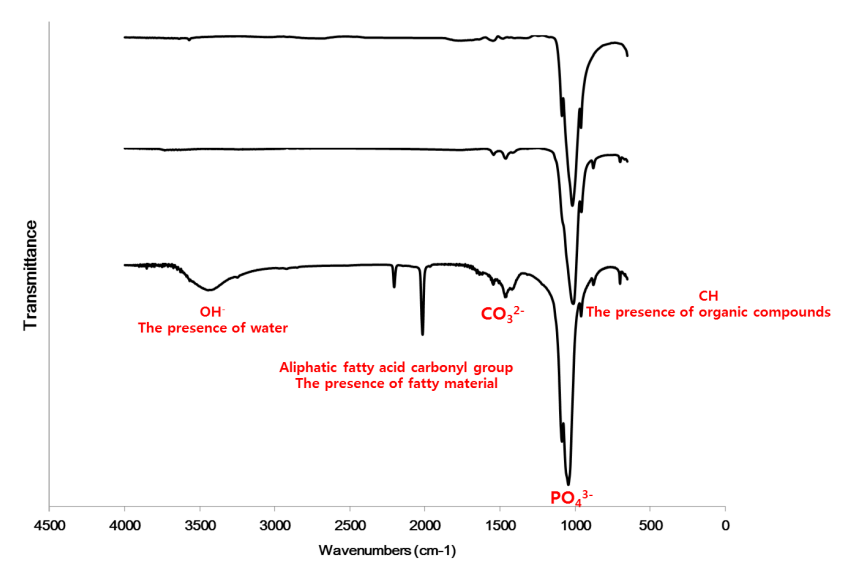

(a)

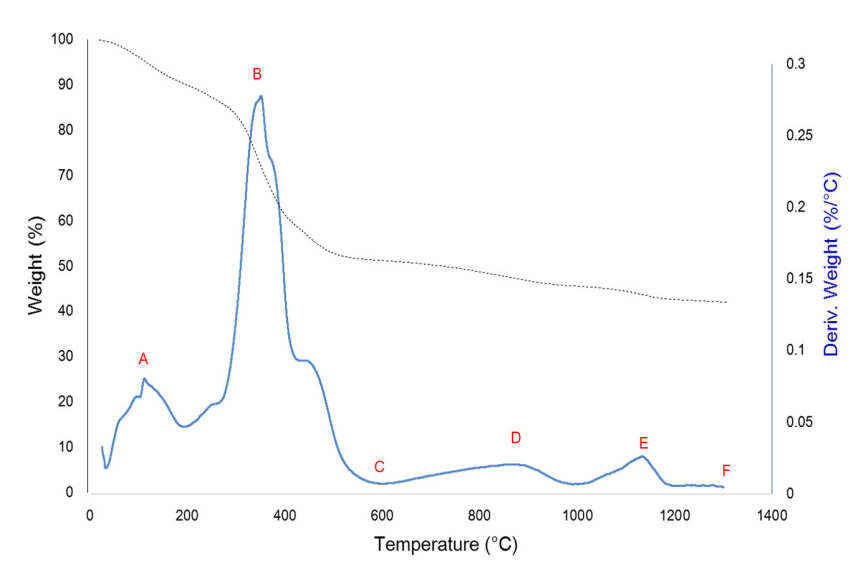

(b)

Figure 6. (a) FT-IR spectra according to the sintering time steps with $4 \mathrm{~h}$. (b) TGA curve (black) and Derivative weight (blue) graph of horse bones. A: Water evaporation, B: Thermal reaction of organic compounds, C: Elimination of organic compounds, D: Chemical decomposition, E: Additional chemical decomposition, F: TCP appearance. 
$600^{\circ} \mathrm{C}, 900^{\circ} \mathrm{C}, 1100^{\circ} \mathrm{C}$, and $1300^{\circ} \mathrm{C}$ were selected as sintering temperature test groups.

All of the FT-IR spectrum of HBPs sintered at $600^{\circ} \mathrm{C}$ (HB 600), $900^{\circ} \mathrm{C}(\mathrm{HB} 900), 1100^{\circ} \mathrm{C}$ (HB 1100), and $1300^{\circ} \mathrm{C}$ (HB 1300) with control groups (HA and Bio-Oss) were alike (data not shown). Same bands with previous studies appeared at around $3570 \mathrm{~cm}^{-1}, 1455 \mathrm{~cm}^{-1}, 1416$ $\mathrm{cm}^{-1}, 1088 \mathrm{~cm}^{-1}, 1017 \mathrm{~cm}^{-1}, 963 \mathrm{~cm}^{-1}$, and $875 \mathrm{~cm}^{-1}$. HA and HB 1300 showed absence of $\mathrm{CO}_{3}{ }^{2-}$ bands. Bio-Oss, which was initially made from the bovine bone sintered at $600^{\circ} \mathrm{C}$ showed almost same bands with HB 600. In particular, the $\mathrm{CO}_{3}{ }^{2-}$ bands were reduced according to the increase of sintering temperature. It could be attributed to the decomposition of carbonated calcium phosphate apatites $\left(\mathrm{Ca}_{10}\left(\mathrm{PO}_{4}\right)_{6} \mathrm{CO}_{3}\right)$ (Lafon, Champion, BernacheAssollant, Gibert, \& Danna, 2003).

Figure 7(b) shows the XRD patterns of HB 600, HB 900, HB 1100, and HB 1300 with control groups (HA and Bio-Oss). The XRD patterns of HB 600 were completely corresponded to the XRD patterns of HA and Bio-Oss. The XRD patterns of HB 900 and HB 1100 showed the presence of $\mathrm{CaO}$ at $37^{\circ}$ meanwhile the $\mathrm{CaO}$ peak was absent in $\mathrm{HB}$
1300. Instead, the peak of calcium oxide phosphate appeared at $30^{\circ}$. It was reported that the reaction between the oxyhydroxyapatite and $\mathrm{CaO}$ occurred at around $1200^{\circ} \mathrm{C}$ according to the following reaction (Lafon et al., 2003):

$$
\begin{aligned}
& \mathrm{Ca}_{10}\left(\mathrm{PO}_{4}\right)_{6}(\mathrm{OH})_{2-2 \mathrm{x}} \mathrm{O}_{\mathrm{x}} \\
& \rightarrow 2 \mathrm{Ca}_{3}\left(\mathrm{PO}_{4}\right)_{2}+\mathrm{Ca}_{4} \mathrm{O}\left(\mathrm{PO}_{4}\right)_{2}+(1-\mathrm{x}) \mathrm{H}_{2} \mathrm{O}
\end{aligned}
$$

Chemical compositions of the samples were presented in Table 3. Generally, the $\mathrm{Ca} / \mathrm{P}$ molar ratio was higher in horse bone samples than in $\mathrm{HA}$. And the $\mathrm{Ca} / \mathrm{P}$ ratio increased according to the increase of the sintering temperature, except for HB 1100. It would be attributed to the $\mathrm{CaO}$. It was reported that the $\mathrm{CaO}$ contents increased with the increasing sintering temperature (Haberko et al., 2006).

In summary, sintering temperature influenced strongly on the resultant HBPs. In particular, $\mathrm{Ca} / \mathrm{P}$ molar ratio increased according to the increase of the sintering temperature due to increase of $\mathrm{CaO}$ except for HB 1100. Further study is required to find out the reason.

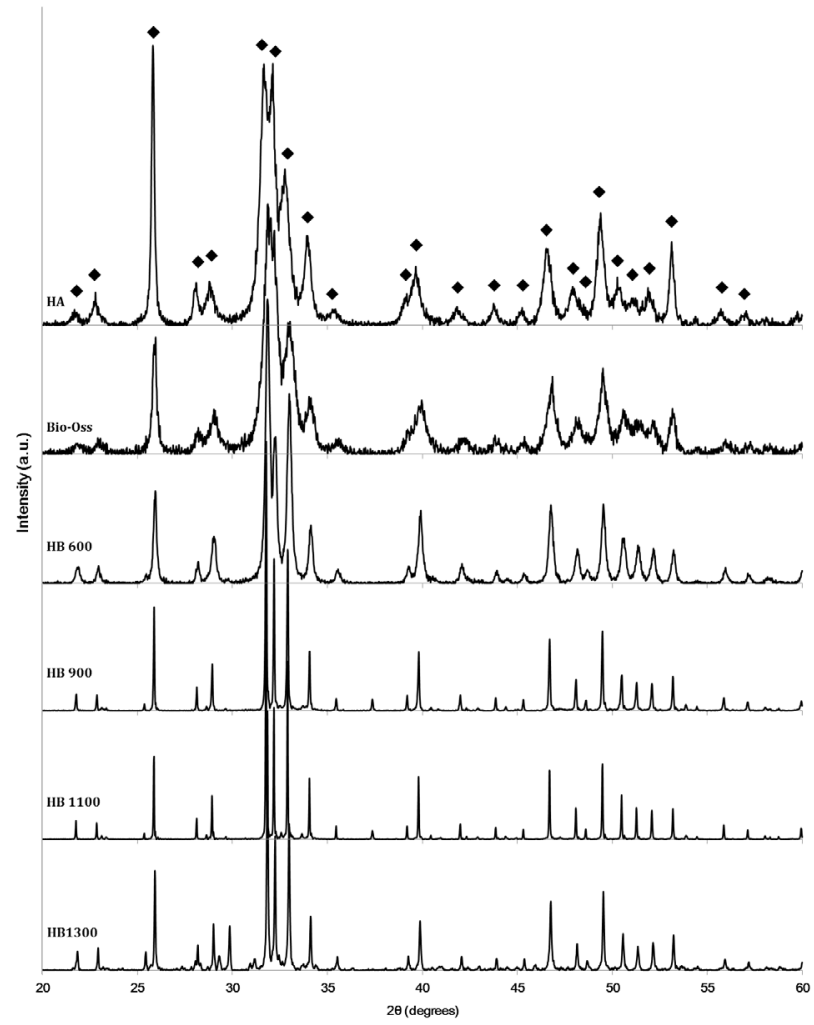

(b)

Figure 7. (a) FT-IR spectra of horse bone powders with different sintering temperature and control groups (HA and Bio-Oss). (b) XRD patterns according to the sintering temperature. ( $\$$ : Characteristic peaks of hydroxyapatite). 
Table 3. Elemental composition according to the sintering temperature

\begin{tabular}{|c|c|c|c|c|c|}
\hline \multirow{2}{*}{ Formula } & \multicolumn{5}{|c|}{ Concentration (wt.\%) } \\
\hline & $\mathrm{HA}$ & HB 600 & HB 900 & HB 1100 & HB 1300 \\
\hline $\mathrm{Ca}$ & ${ }^{d} 38.050 \pm 0.056$ & ${ }^{\mathrm{b}} 42.227 \pm 0.122$ & ${ }^{\mathrm{b}} 42.193 \pm 0.095$ & ${ }^{c} 41.567 \pm 0.038$ & ${ }^{\mathrm{a}} 42.993 \pm 0.031$ \\
\hline $\mathrm{O}$ & ${ }^{\mathrm{a}} 40.700 \pm 0.000$ & ${ }^{c} 39.367 \pm 0.058$ & ${ }^{d} 39.267 \pm 0.058$ & ${ }^{b} 39.567 \pm 0.058$ & ${ }^{\mathrm{e}} 39.100 \pm 0.000$ \\
\hline $\mathrm{P}$ & ${ }^{a} 19.267 \pm 0.023$ & ${ }^{\mathrm{c}} 16.910 \pm 0.066$ & ${ }^{d} 16.787 \pm 0.065$ & ${ }^{\mathrm{b}} 17.217 \pm 0.023$ & ${ }^{\mathrm{e}} 16.510 \pm 0.010$ \\
\hline $\mathrm{Na}$ & ${ }^{a} 1.870 \pm 0.017$ & ${ }^{d} 0.803 \pm 0.008$ & $\mathrm{~b}_{1} .077 \pm 0.012$ & ${ }^{c} 1.020 \pm 0.010$ & ${ }^{d} 0.824 \pm 0.009$ \\
\hline $\mathrm{Mg}$ & ${ }^{d} 0.025 \pm 0.001$ & ${ }^{\mathrm{a}} 0.424 \pm 0.001$ & ${ }^{b} 0.417 \pm 0.004$ & ${ }^{\mathrm{a}} 0.426 \pm 0.002$ & ${ }^{d} 0.393 \pm 0.006$ \\
\hline $\mathrm{Al}$ & ${ }^{b} 0.000 \pm 0.000$ & ${ }^{b} 0.000 \pm 0.000$ & ${ }^{b} 0.000 \pm 0.000$ & ${ }^{b} 0.000 \pm 0.000$ & ${ }^{\mathrm{a}} 0.016 \pm 0.014$ \\
\hline Others & $0.046 \pm 0.009$ & $0.278 \pm 0.004$ & $0.276 \pm 0.006$ & $0.216 \pm 0.005$ & $0.147 \pm 0.004$ \\
\hline $\mathrm{Ca} / \mathrm{P}$ molar ratio & 1.526 & 1.930 & 1.943 & 1.866 & 2.013 \\
\hline
\end{tabular}

- Means with the same letter are not significantly different.
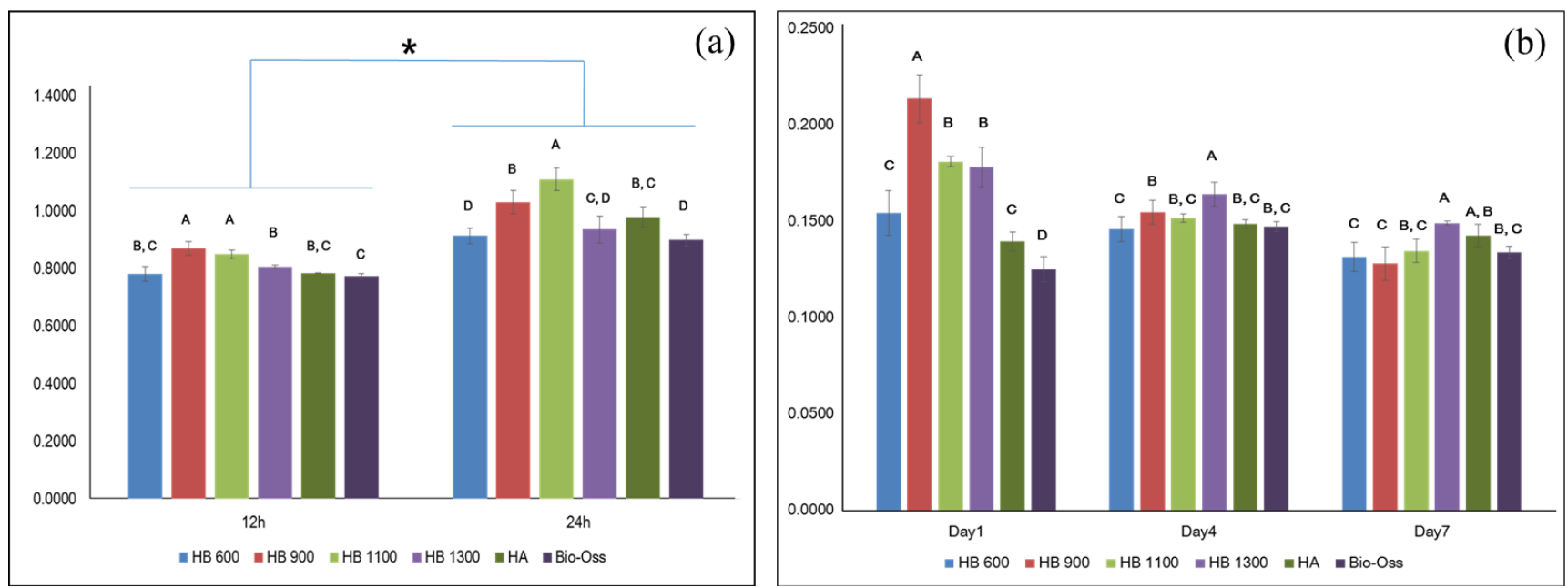

Figure 8. (a) Cell viability on the horse bone powders sintered at the different temperature, arranged by the times (hours) with different sintering temperature samples and control groups (HA and Bio-Oss). (b) Cell proliferation on the horse bone powders sintered at the different temperature, arranged by days with different sintering temperature samples and control groups (HA and Bio-Oss). Means with the same letter are not significantly different. Error bars represent standard deviation, $n=3$.

\section{In vitro test}

\section{Cytotoxicity test}

The results of the WST cytotoxicity assay using MC3T3-E1 osteoblast-like cells are shown in Figure 8(a). At hour 12, HB 900 and HB 1100 showed significantly lower toxicity whereas HB 600 and HB 1300 showed almost same cytotoxicity compared to HA and Bio-Oss. At hour 24, HB 1100 showed the lowest cytotoxicity. Likewise, HB 600 and HB 1300 showed similar cytoxicity with control group. It would be assumed that the $\mathrm{CaO}$ might influence on the cytotoxicity because HB 900 and HB 1100 had higher $\mathrm{CaO}$ contents than $\mathrm{HB} 600$ and $\mathrm{HB} 1300$, which is consistent with cytotoxicity results.

\section{Cell viability test}

Cell viability test was assessed to evaluate the effect of
HBPs according to sintering temperature. In contrast with the cell toxicity test, Figure 8(b) shows that cell viability of samples decreased according to the days. The control groups maintained almost same cell viability or showed the increased cell viability.

HB 900 showed the highest cell viability at 1 day. However, at 4 and 7 days, cell viability of HB 1300 showed the most promoted cell viability. In particular, the HBPs showed better cell viability in 1 day, and HB 1100 and HB 1300 maintained the similar or better cell viability in 4 days and 7 days. The decrease on cell viability of samples would be due to the non-treated surface or PDMS. Actually, $\mathrm{HA}$ and Bio-Oss are chemically synthesized, which have agglomerated cluster of sharp HA unit. Their hedgehoglike surface, on which it seems cells not to adhere, would contribute to their lower cell viability. Meanwhile, HB 
1100 and 1300 had sleek surface, which would provide sufficient cell-adhering site, which gives rise to similar or better cell viability compared with the control groups. Based on the above results, although initial cell adhesion would be better using HB 900 or HB 1100, HB 1300 would be the most suitable for more long-term cell viability.

\section{Conclusion}

In this study, the HBPs production process was investigated and optimized. Bone types did not strongly affect the chemical composition of HBPs. Hot water pretreatment was selected owing to its shortest time to remove residual organic compounds. It was found that the sintering time should exceed at least 12 hours to clearly remove residual organic compounds. The blade grinder method allowed to fabricate HBPs with uniform sizes as well as showed high efficiency. The sintering temperature above $900^{\circ} \mathrm{C}$ was suitable for animal cell culture. Especially, HBPs sintered at $1300^{\circ} \mathrm{C}$ showed highest cell viability. Finally, the optimizing processing condition to prepare regular horse bone-derived HBPs was proposed as follows: (i) cutting the flesh à (ii) washing with distilled water for 48 $\mathrm{h}$ à (iii) hot water pretreatment for $2 \mathrm{~h}$ à (iv) cleaning with distilled water one more and drying à ( $\mathrm{v}$ ) sintering for 12 $\mathrm{h}$ at $1300^{\circ} \mathrm{C}$ à (vi) grinding with blade grinder.

\section{Conflict of Interest}

No potential conflict of interest relevant to this article was reported.

\section{Acknowledgement}

This research was supported by Technology Development Program for Korea Institute of Planning and Evaluation for Technology in Food, Agriculture, Forestry and Fisheries (IPET), Republic of Korea (312031-3).

\section{References}

Bahrololoom, M. E., Javidi, M., Javadpour, S and J. Ma.
2009. Characterisation of natural hydroxyapatite extracted from bovine cortical bone ash. Journal of Ceramic Processing Research, 10(2):129-138.

Baik, S. J. 2011. Development of Fast-Hardening Calcium Phosphate Cement Using Sintered Animal Bone Powders and Chitosan Solution for Bone Tissue Engineering. (The Degree of Master A Thesis for the Degree of Master), Seoul National University, Seoul.

Barakat, N. A. M., Khalil, K. A., Sheikh, F. A., Omran, A. M., Gaihre, B., Khil, S. M and H. Y. Kim. 2008. Physiochemical characterizations of hydroxyapatite extracted from bovine bones by three different methods: Extraction of biologically desirable HAp. Materials Science \& Engineering C-Biomimetic and Supramolecular Systems, 28(8):1381-1387. doi: DOI 10.1016/j.msec.2008.03. 003.

Betz, R. R. 2002. Limitations of autograft and allograft: new synthetic solutions. Orthopedics, 25(5 Suppl), s561-570.

Cai, Y. R., Liu, Y. K., Yan, W. Q., Hu, Q. H., Tao, J. H., Zhang, M and R. K. Tang. 2007. Role of hydroxyapatite nanoparticle size in bone cell proliferation. Journal of Materials Chemistry, 17(36):3780-3787. doi: Doi 10.1039/B705129h.

Danilchenko, S., Koropov, A., Protsenko, I. Y., Sulkio-Cleff, $B$ and L. Sukhodub. 2006. Thermal behavior of biogenic apatite crystals in bone: An X-ray diffraction study. Crystal Research and Technology, 41(3):268-275.

Fernandez-Moran, H and A. Engstrom. 1957. Electron microscopy and x-ray diffraction of bone. Biochim Biophys Acta, 23(2):260-264.

Guizzardi, S., Montanari, C., Migliaccio, S., Strocchi, R., Solmi, R., Martini, D and A. Ruggeri. 2000. Qualitative assessment of natural apatite in vitro and in vivo. $J$ Biomed Mater Res, 53(3):227-234.

Haberko, K., Bućko, M. M., Brzezińska-Miecznik, J., Haberko, M., Mozgawa, W., Panz, T and J. Zarębski. 2006. Natural hydroxyapatite-its behaviour during heat treatment. Journal of the European Ceramic Society, 26(4):537-542.

Johnell, 0 and J. A. Kanis. 2006. An estimate of the worldwide prevalence and disability associated with osteoporotic fractures. Osteoporos Int, 17(12):1726-1733. doi: 10.1007/s00198-006-0172-4.

Kim, H., Rey, C and M. J. Glimcher. 1996. X-ray diffraction, electron microscopy, and Fourier transform infrared spectroscopy of apatite crystals isolated from chicken and bovine calcified cartilage. Calcif Tissue Int, 59(1): 
58-63.

Lafon, J. P., Champion, E., Bernache-Assollant, D., Gibert, R and A. M. Danna. 2003. Termal decomposition of carbonated calcium phosphate apatites. Journal of Thermal Analysis and Calorimetry, 72(3):1127-1134.

Laird, D. F. 2010. Reinforced Sintered Cancellous Bovine Bone as a Potential Bone Replacement Material. University of Waikato.

Langer, R and J. P. Vacanti. 1993. Tissue engineering. Science, 260(5110):920-926.

Laquerriere, P., Kilian, L., Bouchot, A., Jallot, E., Grandjean, A., Guenounou, M and P. Bonhomme. 2001. Effect of hydroxyapatite sintering temperature on intracellular ionic concentrations of monocytes: A TEM-cryo-x-ray microanalysis study. Journal of biomedical materials research, 58(3):238-246.

Mezahi, F. Z., Oudadesse, H., Harabi, A., Lucas-Girot, A., Le Gal, Y., Chaair, H and G. Cathelineau. 2009. Dissolution kinetic and structural behaviour of natural hydroxyapatite vs. thermal treatment. Journal of Thermal Analysis and Calorimetry, 95(1):21-29. doi: DOI 10.1007/ s10973-008-9065-4.

Mondal, S., Mondal, B., Dey, A and S. S. Mukhopadhyay. 2012. Studies on Processing and Characterization of Hydroxyapatite Biomaterials from Different Bio Wastes. Journal of Minerals \& Materials Characterization, 55-67.

Moore, W. R., Graves, S. E and G. I. Bain. 2001. Synthetic bone graft substitutes. ANZ J Surg, 71(6):354-361.

Ooi, C. Y., Hamdi, M and S. Ramesh. 2007. Properties of hydroxyapatite produced by annealing of bovine bone. Ceramics international, 33(7):1171-1177. doi: DOI 10.1016/j.ceramint.2006.04.001.

Ozawa, M and S. Suzuki. 2002. Microstructural Development of Natural Hydroxyapatite Originated from Fish-Bone Waste through Heat Treatment. Journal of the American Ceramic Society, 85(5):1315-1317.

Panda, N. N., Pramanik, K and L. B. Sukla. 2013. Extraction and characterization of biocompatible hydroxyapatite from fresh water fish scales for tissue engineering scaffold. Bioprocess Biosyst Eng, 1-8. doi: 10.1007/ s00449-013-1009-0.

Quarles, L. D., Yohay, D. A., Lever, L. W., Caton, R and R. J. Wenstrup. 1992. Distinct proliferative and differentiated stages of murine MC3T3-E1 cells in culture: An in vitro model of osteoblast development. Journal of Bone and Mineral Research, 7(6):683-692.

Rodrigues, C., Serricella, P., Linhares, A., Guerdes, R., Borojevic, R., Rossi, M and M. Farina. 2003. Characterization of a bovine collagen-hydroxyapatite composite scaffold for bone tissue engineering. Biomaterials, 24(27):4987-4997.

Shi, Z., Huang, X., Cai, Y., Tang, R and D. Yang. 2009. Size effect of hydroxyapatite nanoparticles on proliferation and apoptosis of osteoblast-like cells. Acta Biomater, 5(1):338-345. doi: 10.1016/j.actbio.2008.07.023.

Skalak, R and C. Fox. 1988. Tissue Engineering, Alan R. Liss. Inc., New York.

Sobczak, A., Kowalski, Z and Wzorek, Z. 2009. Preparation of hydroxyapatite from animal bones. Acta Bioeng Biomech, 11(4):23-28.

Taniguchi, Y., Tamaki, T., Oura, H., Hashizume, H and A. Minamide. 1999. Sintered bone implantation for the treatment of benign bone tumours in the hand. J Hand Surg Br, 24(1):109-112.

Tsai, W. C., Liao, C. J., Wu, C. T., Liu, C. Y., Lin, S. C., Young, T. H and H. C. Liu. 2010. Clinical result of sintered bovine hydroxyapatite bone substitute: analysis of the interface reaction between tissue and bone substitute. Journal of Orthopaedic Science, 15(2):223-232. doi: DOI 10.1007/ s00776-009-1441-9.

Ueno, Y., Sasaki, S., Shima, Y., Ueyoshi, A., Harada, M., Terao, K and T. Akiyama. 1983. Studies of sintered bone as a bone substitute. Orthop Ceramic Implants, 3:11-16.

Wang, C. Y., Duan, Y. R., Markovic, B., Barbara, J., Howlett, C. R., Zhang, X. D and H. Zreiqat. 2004. Proliferation and bone-related gene expression of osteoblasts grown on hydroxyapatite ceramics sintered at different temperature. Biomaterials, 25(15):2949-2956. doi: DOI 10.1016/j.biomaterials.2003.09.088.

Wang, J., de Boer, J and K. de Groot. 2008. Proliferation and differentiation of MC3T3-E1 cells on calcium phosphate/chitosan coatings. J Dent Res, 87(7):650-654.

Wang, X. Y., Zuo, Y., Huang, D., Hou, X. D and Y. B. Li. 2010. Comparative study on inorganic composition and crystallographic properties of cortical and cancellous bone. Biomedical and Environmental Sciences, 23(6): 473-480. 